\section{EARLY OPENING OF KEW GARDENS}

$U R$ readers are no doubt aware that a movement has been set on foot for the earlier opening of Kew Gardens, a step which, if taken, would, we believe, wholly alter the character of that institution. It would, we feel assured, seriously interfere with all scientific work, and with the uses which we hope will one day be made of the gardens in the mornings by science schools. Moreover, we doubt if there exists any general desire for their early opening, and are inclined to believe that the movement is quite local in its origin and extent. On this subject we are glad to quote the remarks in a recent number of the Economist, both on account of their pertinency and force, and because we rejoice to see the true interests of science alvocated by papers not professedly scientific :-

"The question has been mooted of late whether the Royal Botanic Gardens at Kew could not be opened to the public at an earlier hour than the present time of I p.m. A little reflection will enable those who ask this question to perceive that it can scarcely be answered in the affirmative without inflicting a serious injury on the real utility of the gardens and on the public service. In the first place, all the real work of the gardens has to be done during the hours when they are closed to the public. As it is, this time is barely long enough for the duties which have to be performed in it. To open the gardens in the morning would require a second staff of gardeners and workmen, as strong, or nearly so, as the existing one. Even with this extra assistance and this greatly increased cost, the work could not be as well executed as it is at present. In the next place, as the name of the gardens implies, they are botanic gardens. Besides those who ordinarily frequent the gardens for pleasure, there are many artists and scientific men who visit them for purposes of study; the only time when they can do this with advantage is before the general public are admitted.

"Of late the public has come in rushes of 12,000 to 60,000 in a day. If only 10,000 persons were in the gardens in the forenoon, all work would necessarily be at an end, and it would be impossible to maintain the existing character of the place. As it is, the Botanic Gardens at $\mathrm{Kew}$ are more accessible to visitors than any other public institution. Wcck days and Sundays alike the gates stand open. At the British Museum and the National Gallery-between the hours of opening which and the gardens at Kew comparisons have been drawnthere are many hours and even days when those institutions are necessarily closed to the public for purposes of cleaning, putting in order, and making good the results of the wear and tear of the enormous traffic. But if the heads of those institutions had, like the Director of the Royal Gardens at Kew, to grow what they exhibit, they would doubtless require many more close days than they do at present.

"Nor is it merely the work of maintaining the gardens and grounds in their present efficiency which has to be carried on in those hours during which the gates are closed to the public. It should not be forgotten that the Royal Gardens at Kew have performed services to the British Empire which no other public institution could undertake. The successful introduction of the Cinchona tree into India (a resource to that country the importance of which cannot be over-estimated), the efforts being made at the present time to procure fresh and improved coffee for Ceylon-to single out only two from a host of similar instances in which the Director of Kew Gardens has freely placed his botanical science and invaluable practical knowledge at the service of the public-will show how diversified and extensive the operations of the gardens are. To prevent these being carried out as they are at present, would be a serious injury to the public service. The present Director, Dr. Hooker, and his father, Sir W. T. Hooker, who held the same office before him, have done everything in their power, consistently with the proper maintenance of the gardens in due working order, to facilitate the use of them by the public generally; and in the interest of science as well as for the prosperity of the gardens, it is to be hoped that the public will see the desirableness of being satisfied with the present very ample allowance of opportunity for visiting the Botanic Gardens at Kew, and that they will not insist on acting over again the fable of the goose and the golden eggs for the sake of a little present pleasure."

\section{THE GEOGRAPHICAL DISTRIBUTION OF AURORAE}

$\mathrm{T}$ an interesting paper in Petermann's Mittheilungen for October, Prof. Fritz gives the results of his extensive researches on this subject. The investigation is beset with difficulties, not only from the deficiency of observations, but from their irregularity. While some observers content themselves with noting only the more remarkable displays, others register the faintest light to the north as an aurora. One observer continues his observations for tens of years, while another, whose zeal has been roused during a period of maximum frequency, allows it to cool when a minimum, with its rare and feeble displays, again returns. The research is further complicated by the fact that the appearance is not only dependent on latitude, but undergoes a periodic change, which in the region of most frequent display manifests itself less in diminished number than in diminished intensity of aurora; and because in some places the phenomenon is far more frequently concealed by a cloudy sky than in others.

As far as possible to eliminate these sources of error, Prof. Fritz compares the mean number of observations for any given place with the mean for mid-Europe between $46^{\circ}$ and $55^{\circ}$ lat. (or between the English and Scotch boundary and the Alps) for the same period, by the following formula :-

$$
\mathrm{M}=\frac{\mathrm{C}}{\mathrm{I} 72} \cdot \frac{\mathrm{B}}{\mathrm{E}}=28 \frac{\mathrm{B}}{\mathrm{E}}
$$

where $M$ is the mean calculated frequency for the given place, $C$ the total number of aurora in the author's catalogue for mid-Europe from 1700 to $1871=4830, B$ the number of auroræ for the period of observation for the given place, and $\mathrm{E}$ the number from the author's catalogue for mid-Europe for the same period. Thus, for example, he calculates for Christiania :-

$$
\begin{array}{llll}
1837-1854 & \mathrm{~B}=529 & \mathrm{E}=581 & \mathrm{M}=25.5 \\
1855-1870 & \mathrm{~B}=436 & \mathrm{E}=568 & \mathrm{M}=21.9 \\
1837-1870 & \mathrm{~B}=965 & \mathrm{E}=\mathrm{I}, 149 & \mathrm{M}=23.3
\end{array}
$$

As we have already remarked, a complete agreement of the different mean values is not to be expected, both on account of errors of observation, and from the various local influences of climate and situation. Professor Fritz gives tables of the numbers of observed auroræ, and calculated values of $\mathrm{M}$ for upwards of 200 places in Europe, Asia, and America ; and from these, proceeds to lay down on a chart of the northern hemisphere a series of curves of equal frequency of auroral display, which he calls isochasmen. He discusses with great care the probable value of the observations, and lays down the curves so as to include on either side of them as many observations above as below the required value. But a few instances iwill make his method clearer than any description.

The zone $M=0.1$ passes through the southermost part of Spain, through Calabria, and just north of the south coast of the Black Sca, through the Sea of Aral and Lake Balkchash, south of Saghalien and the Kurile 